\title{
Scrub typhus meningoencephalitis, a diagnostic challenge for clinicians: A hospital based study from North-East India
}

\author{
M. D. Jamil, Masaraf Hussain'1, Monaliza Lyngdoh, Shriram Sharma', Bhupen Barman, P. K. Bhattacharya \\ Departments of Medicine, and ${ }^{1}$ Neurology, NEIGRIHMS, Shillong, Meghalaya, India
}

\begin{abstract}
Central nervous system (CNS) involvement is a known complication of scrub typhus which range from mild meningitis to frank meninigoencephalitis. Aims and objectives: To study the clinical feature, laboratory parameters and response to treatment of scrub typhus meningitis/meningoencephalitis. Methods and Materials: This is a hospital based prospective observational study from North Eastern India. Diagnosis was based on clinical features and positive serological test (Weil's Felix test and IgM antibody card test). Results: 13 patients of scrub typhus with features of meningitis/meningoencephalitis were included. The mean duration of fever before presentation was $5.61 \pm 3.08$ days and $4(30.76 \%)$ patients had eschar. Altered sensorium, headache, seizure and meningeal sign were present in $13(100 \%)$, $13(100 \%), 6(46.15 \%)$ and $10(76.92 \%)$ patients respectively. Mean CSF protein, glucose and Adenosine deaminase was $152.16 \pm 16.88 \mathrm{mg} / \mathrm{dl}, 55.23 \pm 21.7 \mathrm{mg} / \mathrm{dl}$, and $16.98 \pm 7.37 \mathrm{U} / \mathrm{L}$ respectively. Mean total count of CSF leukocyte and lymphocyte percentage was $46.07 \pm 131$ cell/cumm and $98.66 \pm 3.09 \%$ respectively. Tablet doxycycline with or without injection azithromycin was used and that shows good response $15.38 \%$ of patients died and all of them had multi organ dysfunction. Conclusion: Meningoencephalitis is a common manifestation of scrub typhus and diagnosis requires high degree of clinical suspicion which if diagnosed early and specific treatment started, patients usually recover completely with few complications.
\end{abstract}

Key words: Cerebrospinal fluid, meningoencephalitis, scrub typhus

\section{Introduction}

Scrub typhus also known as tsutsugamushi disease is an acute febrile illness caused by Orientia tsutsugamushi. It is a mite born disease characterized by fever with a headache, suffused face, lymphadenopathy, eschar, multi-organ involvement, and rapid response to doxycycline. Scrub typhus is seen in all terrains of the "tsutsughamushitriangle" which extend from Pakistan, India and Nepal in the West, to South-Eastern Siberia, Japan, China and Korea in the North to Indonesia, the

\section{Address for correspondence:}

Dr. Masaraf Hussain, Department of Neurology, NEIGRIHMS, Shillong, Meghalaya, India.

E-mail: masarafhussain@yahoo.co.in

\begin{tabular}{|l|l|}
\hline \multicolumn{2}{|c|}{ Access this article online } \\
\hline Quick Response Code: & Website: \\
\hline & www.ruralneuropractice.com \\
\cline { 2 - 2 } & \\
\hline
\end{tabular}

Philippines, Northern Australia and the Pacific Islands in the South, and is related mostly to agricultural and outdoor activities. ${ }^{[1,2]}$ In the state of Meghalaya situated in North East India, this disease is well-known among the local people as "niangsohot" since long-time, which means organism associated with chestnut, and had several outbreaks in recent past especially during the month of October to December. ${ }^{[3]}$ Though the infection manifest clinically as a nonspecific febrile illness, serious complications with multisystem involvement may occur.

Central nervous system (CNS) involvement is a known complication of scrub typhus which ranges from meningitis to frank meningoencephalitis. ${ }^{[4,5]}$ The

This is an open access article distributed under the terms of the Creative Commons Attribution-NonCommercial-ShareAlike 3.0 License, which allows others to remix, tweak, and build upon the work non-commercially, as long as the author is credited and the new creations are licensed under the identical terms.

For reprints contact: reprints@medknow.com

How to cite this article: Jamil MD, Hussain M, Lyngdoh M, Sharma S, Barman B, Bhattacharya PK. Scrub typhus meningoencephalitis, a diagnostic challenge for clinicians: A hospital based study from North-East India. J Neurosci Rural Pract 2015;6:488-93. 
name "typhus" itself, is derived from the Greek word "typhos," which means stupor. Other neurological complications include seizure, cranial nerve deficits, vasculitic cerebral infarct, brain hemorrhages, polyneuropathy, sensorineural hearing loss, meningitis or meningoencephalitis. ${ }^{[4,6-8]}$ These manifestations may be due to direct invasion of CNS by the organism as has been shown by polymerase chain reaction (PCR) of cerebrospinal fluid (CSF $)^{[8]}$ or may be due to the unique propensity of the organism to infect vascular endothelial cells, thereby causing microinfarct. ${ }^{[9]}$ Scrub typhus meningitis/meningoencephalitis remains an unclear entity and diagnosis have to be based on [Figure 1] clinical features, especially on the presence of an "eschar" and positive serological test for scrub typhus. Although the organism can be detected in clinical specimens, serological tests are still an indispensable tool for diagnosis. Microimmunofluorescence is considered as the test of choice. Latex agglutination, immunoperoxidase assay, enzyme-linked immunosorbent assay, and PCR are other tests available. However, these are not readily available, and their complexity limits their use to a small number of centers. The Weil-Felix test using the Proteus OXK strain is a commercially available serodiagnostic test. A minimum positive titer is 1:80 or a four-fold rise over previous levels is significant. Several studies have shown that Weil-Felix test has a high specificity. ${ }^{[10]}$ Other test that helps in rapid diagnosis with the good sensitivityis lateral flow format immunochromatographic test (ICT) for the detection of O. tsutsugamushi IgM, IgG and IgA antibodies. ${ }^{[11]}$

As scrub typhus is a well-known mite borne disease in the state of Meghalaya with varieties of manifestations, we hereby made an effort to study about the CNS manifestations of this disease, which if detected timely and managed appropriately will result in rapid reversal of symptoms without any permanent sequelae.

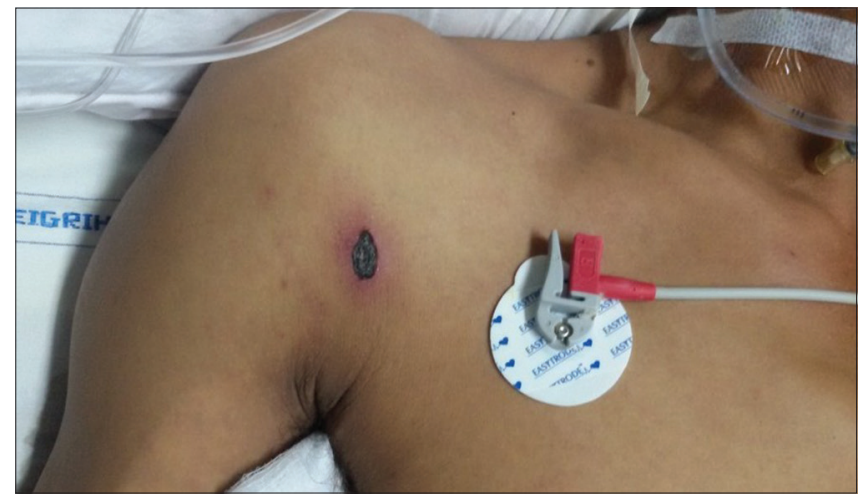

Figure 1: Eschar

\section{Aims and objectives}

To study the clinical features, laboratory parameters and response to treatment of scrub typhus meningitis/meningoencephalitis.

\section{Materials and Methods}

This is a hospital based prospective observational study undertaken in Department of Medicine and Neurology, in a tertiary care center, Shillong, from the period January 1, 2013 to December 31, 2014.

\section{Inclusion criteria}

All patients above 12 years of age admitted in the Department of Neurology and General Medicine with diagnosis of scrub typhus and having features of meningitis/meningoencephalitis.

\section{Exclusion criteria}

Patients having associated CNS diseases not related to scrub typhus (i.e., tumor, neurocysticercosis, epilepsy, etc.).

Cases where CSF analysis was not done.

Meningitis/meningoencephalitis were clinically defined by the presence of headache, and/or nuchal rigidity, with either altered sensorium or focal neurological deficits.

\section{Multiple-organ dysfunction syndrome}

Dysfunction of more than one organ, requiring intervention to maintain homeostasis.

\section{Acute kidney injury}

A rise in serum creatinine of more than $1.6 \mathrm{mg} / \mathrm{dl}$ or urine output $<400 \mathrm{ml} / 24 \mathrm{~h}$ failing to improve after adequate rehydration.

\section{Acute respiratory distress syndrome}

Bilateral alveolar or interstitial infiltrates on chest radiograph and $\mathrm{PaO}_{2} / \mathrm{FiO}_{2} \leq 200 \mathrm{mmHg}$.

\section{Hepatitis}

Rise in serum glutamic oxaloacetic transaminase (SGOT) and serum glutamic pyruvic transaminase (SGPT) of more than 3 times the upper normal limit and/or elevation of serum bilirubin $>3$ times the upper limit of normal value.

Diagnosis of scrub typhus has been made if a patient falls in any of the following three groups:

Group A: Acute febrile illness with eschar specific for scrub typhus plus serological test positive for scrub 
typhus (Weil-Felix test titer for OXK $\geq 1: 160$ or positive immunochromatographic card test for detection of IgM antibodies to O. tsutsugamushi).

Group B: Acute febrile illness + Weil-Felix test titer for OXK $\geq 1: 320$.

Group C: Acute febrile illness highly suspicious of scrub typhus plus positive immunochromatographic card test for detection of IgM antibodies to O. tsutsugamushi plus response to doxycycline/azithromycin.

CSF analysis was done in scrub typhus cases with clinical features defining meningitis/meningoencephalitis. Also to cell counts, CSF protein, and glucose estimation was done. CSF was also analyzed for Grams stain, Ziehl-Neilsen and Indian Ink stain. CSF adenosine deaminase (ADA) could not be done in all cases due to logistic reasons.

Demographic data, history, examination and investigations were noted and stored in an Excel spreadsheet for analysis. Mean values are mentioned with \pm one standard deviation.

\section{Results and Observations}

During the study period, 113 patients were diagnosed to have scrub typhus out of which 15 (13.2\%) patients had clinical feature suggestive of meningoencephalitis. However after examination and investigation only 13 patients were included in the study as per inclusion and exclusion criteria.

Age and gender distribution along with some important blood investigations finding and diagnostic grouping are shown in Table 1.

In the present study, the mean age of patients was $34.84 \pm 16.21$ years and male:female ratio 2.25:1. The majority of the cases were reported from the month of October to November and most of the cases were involved in outdoor activities like collecting wood from the jungle, fishing, and agriculture activities. Fever was documented in all cases and mean duration of fever at the time of presentation was $5.61 \pm 3.08$ days. The pathognomonic "eschar" was detected in four numbers of patients with meningoencephalitis (30.77\%); among them 1 patient had two eschars and rest had single. It was also found in 1 patient clinically suspected to have meningoencephalitis, however since the CSF study was not done; case could not be included in the study. The site of "eschar" was in various locations like inguinal, axilla, around the umbilicus, right shoulder, and natal cleft.
Altered sensorium in the form of reduced level of consciousness, abnormal behaviors, agitation, irritability or irrelevant talk was documented in all cases along with a headache. Headache was reported be holocranial in the majority of cases. Nuchal rigidity was noted in $10(76.92 \%)$ number of cases, of which 4 (30.77\%) patients had associated Kernig's sign. Generalized seizure was documented in $6(46.15 \%)$ number of cases of which $5(38.46 \%)$ cases had single episode and $1(7.69 \%)$ patient had several episodes of seizures. Myoclonic jerky movement involving the lower limb was noted in $1(7.69 \%)$ patient. Cranial nerve deficit was found in 1 patient in the form of bilateral lateral rectus palsy $(7.69 \%)$.

Other features noted were lymphadenopathy $(46.15 \%)$, icterus $(53.85 \%)$, hepatomegaly $(38.46 \%)$, splenomegaly $(7.69 \%)$, pulmonary edema $(23.08 \%)$, oliguria (15.38\%) and epistaxis $(7.69 \%)$.

However on laboratory investigation, all patients were found to have deranged liver function test. This was most commonly reflected by an increase in liver enzymes SGOT and SGPT (SGOT showing more rise than SGPT), which was found in all patients. Serum bilirubin was raised in 8 patients $(61.54 \%)$, which was mostly of direct bilirubinemia. Renal function test was deranged in 5 patients $(38.46 \%$ ) in the form of increased serum creatinine, of which 2 patients had symptoms of oliguria. On the radiological study of chest features of pulmonary edema were present in $3(23.08 \%)$ patients.

CSF analysis was done in 13 patients of scrub typhus with clinical suspicion of meningitis/meningoencephalitis, after fundus examination. CSF analysis finding along with other neurological features and patients outcome of all patients are shown in Table 2. The mean CSF protein, glucose, cell count were $152.16 \pm 66.88 \mathrm{mg} / \mathrm{dl}$, $55.23 \pm 12.7 \mathrm{mg} / \mathrm{dl}$, and $46.07 \pm 131$ cells/cumm of CSF respectively with lymphocyte count of more than $98 \%$ in all except one. Most patients had lymphocytic pleocytosis and mean lymphocyte percentage was $98.66 \% \pm 3.09 \%$. CSF ADA levels were available for 9 patients, all patients had CSF ADA level of more than $10 \mathrm{U} / \mathrm{L}$ except one and mean CSF ADA for these 9 patients was $16.98 \pm 7.37 \mathrm{U} / \mathrm{L}$. Neuroimaging in the form of noncontrast computed tomography brain and magnetic resonance imaging brain were done in all 13 and 2 patients respectively, but all reports were normal. Among the major non neurological complications; 2 (15.38\%), 5 (38.46\%) and 9 (69.23\%) patients had acute respiratory distress syndrome, acute kidney injury (AKI), and hepatitis respectively. Out of all 13 patients, $11(84.61 \%)$ patients recovered and $2(15.38 \%)$ patients expired. Both 2 patients who expired had multiple-organ dysfunctions. 
Table 1: Diagnostic categories

\begin{tabular}{|c|c|c|c|c|}
\hline Case no & Age (in years) & Gender & Investigation Findings & Diagnostic category \\
\hline$\overline{\mathrm{CN} 1}$ & 18 & Female & $\begin{array}{l}\text { TC-10800;DLC-N40L54,M6; Platlet-80,000/cumm, CXR-Pleural Effusion, } \\
\text { BIL-2.3, SGOT-534,SGPT-229,ALKP-697, Sr Creat-0.9, BI Urea-46. }\end{array}$ & Group B \\
\hline CN2 & 56 & Male & $\begin{array}{l}\text { TC-10,700; DLC-N82,L10,M6,E2; Platlet-70,000/cumm, CXR - B/L Hazy, } \\
\text { BIL-4.2, SGOT-323,SGPT-112,ALKP-646, Sr Creat-7.5, BI Urea-185. }\end{array}$ & Group A \\
\hline CN3 & 22 & Female & $\begin{array}{l}\text { TC-17,800;DLC-N80,L20, Platlet-1,50,000/cumm, , Pleural Effusion, BIL- } \\
\text { 6.1, SGOT-581,SGPT-152,ALKP-220, Sr Creat-0.6, BI Urea -20. }\end{array}$ & Group B \\
\hline CN4 & 23 & Female & $\begin{array}{l}\text { TC-8,000;DLC-N40L50,M6,E4,B6 Platlet-60,000/cumm, CXR-Pleural } \\
\text { Effusion, BIL-0.4, SGOT-456,SGPT-86,ALKP-90, Sr AMY-342, Sr LIP-314, } \\
\text { Sr Creat-1.1, BI Urea-47. }\end{array}$ & Group C \\
\hline CN5 & 75 & Male & $\begin{array}{l}\text { TC-7000; DLC-N20L75,M5, Platlet-200,000/cumm, BIL-0.6, SGOT- } \\
\text { 112,SGPT-35,ALKP-230, Sr AMY-53, Sr LIP-35, Creat-1.1, BI Urea-43. }\end{array}$ & Group C \\
\hline CN6 & 30 & Male & $\begin{array}{l}\text { TC-9000; DLC-N57L39,M4; Platlet-60,000/cumm; CXR-B/L Lung Opacity, } \\
\text { BIL-6.7, SGOT-246,SGPT-99,ALKP-741, Creat-0.9, BI Urea-33. }\end{array}$ & Group C \\
\hline CN7 & 23 & Male & $\begin{array}{l}\text { TC-12800; DLC-N87L9,M3,E1; Platlet-50,000/cumm; CXR-B/L Lung } \\
\text { Opacity, BIL-3,6, SGOT-286,SGPT-97,ALKP-261, Creat-0.9, BI Urea-43. }\end{array}$ & Group A \\
\hline CN8 & 40 & Male & $\begin{array}{l}\text { TC-4800; DLC-N94L6; Platlet-130,000/cumm, BIL-3.2, SGOT-267,SGPT- } \\
\text { 77,ALKP-101, Creat-7.5, BI Urea-193. }\end{array}$ & Group A \\
\hline \multirow[t]{2}{*}{ CN9 } & 38 & Male & TC-10300; DLC-N76L15,M8,E1; & Group B \\
\hline & & & $\begin{array}{l}\text { Platlet-3,50,000/cumm, BIL-1.78, SGOT-183,SGPT-141,ALKP-195, } \\
\text { Creat-6.8, BI Urea-211. }\end{array}$ & \\
\hline CN10 & 32 & Female & $\begin{array}{l}\text { TC-8600;DLC-N56L36,M6,E2; Platlet-150,000/cumm, BIL-14.9, SGOT- } \\
\text { 420,SGPT-163,ALKP-189, Sr AMY-162, Sr LIP-57, Creat-4.6, BI Urea-174. }\end{array}$ & Group C \\
\hline CN11 & 50 & Female & $\begin{array}{l}\text { TC-10000; DLC-N85L12,M3; Platlet-330,000/cumm, B/L Pleural Effusion, } \\
\text { BIL-1.4, SGOT-61,SGPT-66,ALKP-133, Creat-1.3, BI Urea-16. }\end{array}$ & Group B \\
\hline CN12 & 28 & Male & $\begin{array}{l}\text { TC-11200; DLC-N87L10,M3; Platlet-90,000/cumm, BIL-6.1, SGOT-316, } \\
\text { SGPT-106, ALKP-266, Creat-2.1, BI Urea-140. }\end{array}$ & Group A \\
\hline CN13 & 18 & Male & $\begin{array}{l}\text { TC-6800; DLC-N76L21,M3; Platlet-150,000/cumm, BIL-1.9, SGOT- } \\
\text { 201,SGPT-90,ALKP-326, Creat-1.0, BI Urea-73. }\end{array}$ & Group C \\
\hline
\end{tabular}

TC: Total leukocyte count(per cumm), DLC: Differential leukocyte count(\%), N: Neutrophils, L: Lymphocytes, M: Monocytes,E: Eosinophils, B: Basophils, BIL: Total bilirubin (in $\mathrm{mg} / \mathrm{dl}$ ), SGOT: Serum glutamic oxaloacetic transaminase(U/L), SGPT: Serum glutamic pyruvic transaminase(U/L), AKLP: Alkaline phosphatise(U/L), Creat: Creatinine(mg/dl), Sr: Serum, BI: Blood, AMY: Amylase(U/L),LIP: Lipase(U/L), B/L: Bilateral,CXR: chest X: Ray, Urea in mg/dl,

In view of the diminished sensorium in the selected patients, injectable azithromycin $500 \mathrm{mg}$ once daily was given initially, and oral doxycycline $100 \mathrm{mg}$ twice daily was added. Azithromycin was stopped after 5 days, and doxycycline was continued for 10 days.

\section{Discussion}

Acute febrile illness with CNS symptom requires timely diagnosis and treatment to prevent mortality and sequelae. CNS involvement is almost reported in all rickettsial diseases such as Rocky Mountain spotted fever, ${ }^{[12]}$ epidemic typhus, ${ }^{[9]}$ murine typhus, ${ }^{[13]}$ scrub typhus and $\mathrm{Q}$ fever. ${ }^{[14]}$ Depends on the predominant cellular target and intracellular niche, Rickettsia rickettsii and Rickettsia prowazekii has predominant CNS manifestation as encephalitis, but O. tsutsugamushi and Coxiella burnetii predominantly manifests as meningoencephalitis. ${ }^{[9]}$

The results have shown the profile of scrub typhus meningoencephalitis from an area already well-known for scrub typhus. The mean duration of fever was $5.61 \pm 3.08$ days prior to the presentation. This is shorter than the mean duration of fever of 7.68 and 8.4 days reported from another study ${ }^{[4,15]}$ and its duration is longer than that of viral encephalitis, or acute bacterial meningitis. ${ }^{[4]}$

Most of the affected patients were males. This may be due to the reason that they are more involved in an outdoor activity like farming, fishing or collecting firewood from the jungle that expose them to mite infested area or vegetation.

Headache is a common symptom in scrub typhus. A severe headache occurs almost invariably and has been used as a key clinical criterion for identifying suspected cases. ${ }^{[9]}$ In the present study, headache was present in all cases similar to one study and was holocranial in nature in the majority of cases. Other studies have reported the occurrence of headache in around $46-77 \%$ of patients. ${ }^{[4,6,15]}$ Headache may also occur in scrub typhus patients without meningitis, ${ }^{[6,15]}$ but it is less severe and does not have other CNS symptoms. Sign of meningeal irritation in the form of neck rigidity and/or Kernig's sign are cardinal clinical features of any meningitis. In the present study, meningeal signs were present in $76.92 \%$ of patients though other studies shown the presence of neck rigidity in $45.45 \%$ and 
Table 2: Clinical manifestations and outcome

\begin{tabular}{|c|c|c|c|c|}
\hline \multirow[t]{2}{*}{ Case no } & \multicolumn{2}{|c|}{ Clinical Manifestations } & \multirow[t]{2}{*}{ CSF Analysis } & \multirow[t]{2}{*}{ Out come } \\
\hline & Non neurological & Neurological & & \\
\hline $\mathrm{CN} 1$ & Hepatitis, splenomegaly & Altered sensorium, headache & $\begin{array}{l}\text { Glu-52, Pro-118, TC-10, DLC- } \\
\text { All L, ADA-16.38 }\end{array}$ & Recovered \\
\hline $\mathrm{CN} 2$ & $\begin{array}{l}\text { Hepatitis, AKI, ARDS } \\
\text { lymphadenopathy }\end{array}$ & $\begin{array}{l}\text { Altered sensorium, headache, kernig's } \\
\text { sign, neck rigidity, seizure }\end{array}$ & $\begin{array}{l}\text { Glu-62,Pro-98, TC-No Cell. } \\
\text { ADA-12.91 }\end{array}$ & Expired \\
\hline CN3 & Hepatitis & $\begin{array}{l}\text { Altered sensorium, headache, bilateral } \\
\text { lateral rectus palsy, neck rigidity }\end{array}$ & $\begin{array}{l}\text { Glu-54, Pro-117, TC-5, } \\
\text { DLC:L99\%, N1\%, ADA-26.19 }\end{array}$ & Recovered \\
\hline CN4 & Cough, Dyspnea & $\begin{array}{l}\text { Altered sensorium, headache, } \\
\text { neck rigidity }\end{array}$ & $\begin{array}{l}\text { Glu-64, Pro-301, TC-50, DLC- } \\
\text { All L, }\end{array}$ & Recovered \\
\hline CN5 & Pain Abdomen & $\begin{array}{l}\text { Altered sensorium, headache, kernig's } \\
\text { sign, neck rigidity, and irrelevant talk }\end{array}$ & $\begin{array}{l}\text { Glu-23, Pro-83.5, TC-8 ,DLC- } \\
\text { All L, ADA-11.06 }\end{array}$ & Recovered \\
\hline CN6 & Hepatitis, ARDS & $\begin{array}{l}\text { Altered sensorium, headache, seizure } \\
\text { several episodes, neck rigidity }\end{array}$ & $\begin{array}{l}\text { Glu-49, Pro-157, TC-No Cell, } \\
\text { ADA-12.04 }\end{array}$ & Recovered \\
\hline CN7 & $\begin{array}{l}\text { Pulmonary edema, loose motion, } \\
\text { hepatitis, lymphadenopathy }\end{array}$ & Altered sensorium, headache & $\begin{array}{l}\text { Glu-63, Pro-127, TC-500,DLC- } \\
\text { L-90\%, N-10\%, ADA-16.56 }\end{array}$ & Recovered \\
\hline CN8 & $\begin{array}{l}\text { Hepatitis,AKI, pain abdomen, } \\
\text { lymphadenopathy }\end{array}$ & $\begin{array}{l}\text { Altered sensorium, headache, neck } \\
\text { rigidity, kernig's sign }\end{array}$ & $\begin{array}{l}\text { Glu-51, Pro-139,TC- } \\
\text { Occasional L, ADA-24. }\end{array}$ & Recovered \\
\hline CN9 & Hepatitis, AKI & $\begin{array}{l}\text { Altered sensorium, headache, seizure, } \\
\text { neck rigidity }\end{array}$ & $\begin{array}{l}\text { Glu-45,Pro-84,TC-15,DLC- L } \\
99 \% \text { And N } 1 \% \text {. }\end{array}$ & Recovered \\
\hline CN10 & Hepatitis, AKI, epistaxsis & Altered sensorium, headache, seizure & $\begin{array}{l}\text { Glu-62, Pro-174, TC-1, DLC- } \\
\text { All L, ADA-33.25 }\end{array}$ & Recovered \\
\hline CN11 & Cough, pain abdomen & $\begin{array}{l}\text { Altered sensorium, headache, kernig's } \\
\text { sign, neck rigidity, and irrelevant talk }\end{array}$ & Glu-97, Pro-103, TC-No Cell & Recovered \\
\hline CN12 & Hepatitis,AKI, lymphadenopathy & $\begin{array}{l}\text { Altered sensorium, headache,seizure, } \\
\text { neck rigidity }\end{array}$ & $\begin{array}{l}\text { Glu-50, Pro-200, TC-8, DLC- } \\
\text { All L, ADA-15.25 }\end{array}$ & Expired \\
\hline CN13 & Hepatitis, lymphadenopathy & $\begin{array}{l}\text { Altered sensorium, headache, } \\
\text { myoclonic jerk, seizure, neck rigidity }\end{array}$ & $\begin{array}{l}\text { Glu-64, Pro-276, TC-3, DLC- } \\
\text { All L. }\end{array}$ & Recovered \\
\hline
\end{tabular}

CSF: Cerebrospinal Fluid, L: Lymphocyte, N: Neutrophils, TC: Total leukocyte count(Per Cumm), DLC: Differential leukocyte count, Glu: Glucose in mg/dl, Pro: Protein in mg/dl, AKI: Acute Kidney Injury, ARDS: Acute respiratory distress syndrome, ADA: Adenosine deaminase(U/L)

$49 \%$ of cases. ${ }^{[15,16]}$ In the present study altered sensorium was seen in all patients similar to finding of one study, but others reported lower incidence of about $56.3 \%{ }^{[4,16]}$ This may be due to the severity of the cases in our series, or referral bias. A seizure is a common finding that occurred in $46.15 \%$ of patients in the present study, all patients had single episode except one. Other reports of seizure in patients with CNS involvement in scrub typhus varies from $22 \%$ to $50 \% \cdot{ }^{[4,5,16]}$ Myoclonus is a rare finding in scrub meningoencephalitis, and only one care is reported in the literature along with Parkinsonism. ${ }^{[17]}$ In the present study, 1 patient (7.69\%) had myoclonic jerky movement involving the lower limb. Cranial nerve involvement in the form of unilateral or bilateral sixth nerve palsy is a common finding in scrub meninigoencephalitis but the report of bilateral facial nerve involvement is also there in literature. In the present study, only 1 patient $(7.69 \%)$ had bilateral sixth nerve palsy. There is also a report of ear symptoms in scrub typhus that includes sensorineural hearing loss; otalgia and tinnitus in 19\% of the patients but in the present study none of the patient complaints of an ear problem. ${ }^{[18]}$

The pathognomic "eschar" that helps in early diagnosis of patients was detected in $30.77 \%$ patients. Eschars are reported from $20 \%$ to $86 \%$ of patients in different studies ${ }^{[6,15,16]}$ one study from North-Eastern India shows the higher percentage in children than the adult population. ${ }^{[3,19]}$ Identification of eschar may be difficult in Indian population due to their dark skin and it is also expected to be less in areas endemic for scrub typhus. The absence of eschar was a risk factor for mortality in a study. ${ }^{[20]}$

Hepatitis and hepatomegaly were the most common associated abnormalities in our study. This is similar to that reported by other studies. Though increase in liver enzymes has been reported in other studies, the disproportionate rise of SGOT over SGPT was detected in our patients. Similar finding has been highlighted in a study form North East India on scrub typhus. ${ }^{[2]}$ AKI is a common complication of scrub typhus with poor outcome, in the present study renal function was deranged in $38.46 \%$ patients.

CSF analysis in scrub typhus meningoencephalitis usually reveals mild to moderate elevation in protein, low to normal glucose and a mild degree of lymphocytic pleocytosis. The absence of neutrophilic pleocytosis helps in differentiating it from bacterial meningitis but differentiating it from tubercular meningitis remains a challenge. The present study shows similar finding except in few cases where no pleocytosis was noted. Tubercular 
meningitis remains the closest differential diagnosis in our setting. Staining for acid-fast Bacilli (AFB) in CSF has low sensitivity and CSF culture for AFB take up to 8 weeks and is positive in only $50-75 \%$ of the cases. ${ }^{[21]}$ Markers like CSF ADA may be helpful in differentiating scrub meningitis from tubercular meningitis as mentioned in some studies. But, in present CSF ADA was found to be elevated in almost all cases $(>10 \mathrm{U} / \mathrm{L})$ for whom CSF ADA report was available and did not help in differentiating scrub typhus meningoencephalitis from tubercular.

Doxycycline remains the drug of choice. However, doxycycline is bacteriostatic to O. tsutsugamushi and does not cross the blood-brain barrier beyond $15-30 \% .{ }^{[22]}$ Sometimes progressive neurological damage has occurred in spite of treatment with doxycycline, ${ }^{[23]}$ either due to resistance, immune mediated injury or due to drug interaction with oral antacids. ${ }^{[24]}$ Injectable azithromycin is a good alternative for condition where doxycycline is contraindicated or having doubtful gastrointestinal absorption. ${ }^{[24]}$ In the present study as most of the patients were critically ill and injectable doxycycline was not available, injectable azithromycin was used in majority along with oral doxycycline. Recovery occurred in $84.61 \%$ of patients and $15.38 \%$ of patients expired. Patients who died had multi-organ dysfunction. Recovery was brisk in scrub typhus meningoencephalitis with appropriate therapy and patient usually shows sign of improvement within $48 \mathrm{~h}$ of initiation of specific therapy.

\section{Conclusion}

Scrub typhus meningoencephalitis is not an uncommon complication of scrub typhus. The majority of the patient present as acute febrile illness with altered sensorium and meningeal sign. Eschar helps in early diagnosis but in majority it remains absent. CSF analysis shows mild to moderate rise in protein with low to normal glucose. CSF Lymphocytic pleocytosis may be helpful in differentiating it from bacterial meningitis, but tubercular meningitis remains a close differential diagnosis. Thus a high degree of clinical suspicion and a positive rapid, diagnostic test remains an important point in the management of scrub typhus as the timely initiation of specific therapy results in complete recovery and fewer complications.

\section{Financial support and sponsorship}

Nil.

\section{Conflicts of interest}

There are no conflicts of interest.

\section{References}

1. Chattopadhyay S, Richards AL. Scrub typhus vaccines: Past history and recent developments. Hum Vaccin 2007;3:73-80.

2. Liu YX, Feng D, Suo JJ, Xing YB, Liu G, Liu LH, et al. Clinical characteristics of the autumn-winter type scrub typhus cases in South of Shandong province, northern China. BMC Infect Dis 2009;9:82.

3. Jamil MD, Lyngrah KG, Lyngdoh M, Hussain M. Clinical manifestations and complications of scrub typhus. A hospital based study from North Eastern. J Assoc Physicians India 2014;62:19-23.

4. Varghese GM, Mathew A, Kumar S, Abraham OC, Trowbridge P, Mathai E. Differential diagnosis of scrub typhus meningitis from bacterial meningitis using clinical and laboratory features. Neurol India 2013;61:17-20.

5. Kar A, Dhanaraj M, Dedeepiya D, Harikrishna K. Acute encephalitis syndrome following scrub typhus infection. Indian J Crit Care Med 2014;18:453-5.

6. Viswanathan S, Muthu V, Iqbal N, Remalayam B, George T. Scrub typhus meningitis in South India - A retrospective study. PLoS One 2013;8:e66595.

7. Kim JH, Lee SA, Ahn TB, Yoon SS, Park KC, Chang DI, et al. Polyneuropathy and cerebral infarction complicating scrub typhus. J Clin Neurol 2008;4:36-9.

8. Pai H, Sohn S, Seong Y, Kee S, Chang WH, Choe KW. Central nervous system involvement in patients with scrub typhus. Clin Infect Dis 1997;24:436-40.

9. Drevets DA, Leenen PJ, Greenfield RA. Invasion of the central nervous system by intracellular bacteria. Clin Microbiol Rev 2004;17:323-47.

10. Mahajan SK, Kashyap R, Kanga A, Sharma V, Prasher BS, Pal LS. Relevance of Weil-Felix test in diagnosis of scrub typhus in India. J Assoc Physicians India 2006;54:619-21.

11. Silpasakorn S, Waywa D, Hoontrakul S, Suttinont C, Losuwanaluk K, Suputtamongkol Y. Performance of SD Bioline Tsutsugamushi assays for the diagnosis of scrub typhus in Thailand. J Med Assoc Thai 2012;95 Suppl 2:S18-22.

12. Kamper CA, Chessman KH, Phelps SJ. Rocky Mountain spotted fever. Clin Pharm 1988;7:109-16.

13. Simon NG, Cremer PD, Graves SR. Murine typhus returns to New South Wales: A case of isolated meningoencephalitis with raised intracranial pressure. Med J Aust 2011;194:652-4.

14. Shaked Y, Samra Y. Q fever meningoencephalitis associated with bilateral abducens nerve paralysis, bilateral optic neuritis and abnormal cerebrospinal fluid findings. Infection 1989;17:394-5.

15. Kim DM, Chung JH, Yun NR, Kim SW, Lee JY, Han MA, et al. Scrub typhus meningitis or meningoencephalitis. Am J Trop Med Hyg 2013;89:1206-11.

16. Misra UK, Kalita J, Mani VE. Neurological manifestations of scrub typhus. J Neurol Neurosurg Psychiatry 2015;86:761-6.

17. Chiou YH, Yang CJ, Lai TH. Scrub typhus associated with transient parkinsonism and myoclonus. J Clin Neurosci 2013;20:182-3.

18. Kang JI, Kim DM, Lee J. Acute sensorineural hearing loss and severe otalgia due to scrub typhus. BMC Infect Dis 2009;9:173.

19. Dass R, Deka NM, Duwarah SG, Barman H, Hoque R, Mili D, et al. Characteristics of pediatric scrub typhus during an outbreak in the North Eastern region of India: Peculiarities in clinical presentation, laboratory findings and complications. Indian J Pediatr 2011;78:1365-70.

20. Lee CS, Hwang JH, Lee HB, Kwon KS. Risk factors leading to fatal outcome in scrub typhus patients. Am J Trop Med Hyg 2009;81:484-8.

21. Thwaites GE, Chau TT, Stepniewska K, Phu NH, Chuong LV, Sinh DX, et al. Diagnosis of adult tuberculous meningitis by use of clinical and laboratory features. Lancet 2002;360:1287-92.

22. Dotevall L, Hagberg L. Penetration of doxycycline into cerebrospinal fluid in patients treated for suspected Lyme neuroborreliosis. Antimicrob Agents Chemother 1989;33:1078-80.

23. Kim DM, Kim YS, Cho HY, Lee YB. Scrub typhus meningoencephalitis occurring during doxycycline therapy for Orientia tsutsugamushi. Diagn Microbiol Infect Dis 2011;69:271-4.

24. Jang MO, Jang HC, Kim UJ, Ahn JH, Kang SJ, Jung SI, et al. Outcome of intravenous azithromycin therapy in patients with complicated scrub typhus compared with that of doxycycline therapy using propensity-matched analysis. Antimicrob Agents Chemother 2014;58:1488-93. 